\title{
Sustainability of a Multi-Component Education Program (ABC of Healthy Eating) after Three Months and Nine Months: The Socioeconomic Context in Improving Nutrition Knowledge in Polish Teenagers
}

\author{
Lidia Wadolowska $^{1,+(\mathbb{D}, \text { Malgorzata Kostecka }}{ }^{2, *,+} \mathbb{D}$, Joanna Kowalkowska ${ }^{1} \mathbb{D}$, Marta Jeruszka-Bielak ${ }^{3} \mathbb{D}$, \\ Marzena Tomaszewska ${ }^{4}\left(\mathbb{D}\right.$, Anna Danielewicz ${ }^{1}{ }^{(D)}$ and Jadwiga Hamulka ${ }^{3}$ (D)
}

1 Department of Human Nutrition, Faculty of Food Science, University of Warmia and Mazury in Olsztyn, Pl. Cieszynski 1, 10-718 Olsztyn, Poland; lidia.wadolowska@uwm.edu.pl (L.W.); joanna.kowalkowska@uwm.edu.pl (J.K.); anna.danielewicz@uwm.edu.pl (A.D.)

2 Department of Chemistry, Faculty of Food Science and Biotechnology, University of Life Sciences, 15 Akademicka Street, 20-950 Lublin, Poland

3 Department of Human Nutrition, Institute of Human Nutrition Sciences, Warsaw University of Life Science (SGGW-WULS), 159C Nowoursynowska Street, 02-787 Warsaw, Poland; marta_jeruszka_bielak@sggw.edu.pl (M.J.-B.); jadwiga_hamulka@sggw.edu.pl (J.H.)

check for updates

Citation: Wadolowska, L.; Kostecka, M.; Kowalkowska, J.; Jeruszka-Bielak, M.; Tomaszewska, M.; Danielewicz, A.; Hamulka, J. Sustainability of a Multi-Component Education Program (ABC of Healthy Eating) after Three Months and Nine Months: The Socioeconomic Context in Improving Nutrition Knowledge in Polish Teenagers. Nutrients 2021, 13, 1661. https://doi.org/10.3390/ nu13051661

Academic Editor:

Santiago Navas-Carretero

Received: 8 April 2021

Accepted: 11 May 2021

Published: 14 May 2021

Publisher's Note: MDPI stays neutral with regard to jurisdictional claims in published maps and institutional affiliations.

Copyright: (c) 2021 by the authors. Licensee MDPI, Basel, Switzerland. This article is an open access article distributed under the terms and conditions of the Creative Commons Attribution (CC BY) license (https:// creativecommons.org/licenses/by/ $4.0 /)$.
4 Department of Food Gastronomy and Food Hygiene, Institute of Human Nutrition Sciences, Warsaw University of Life Science (SGGW-WULS), 159C Nowoursynowska Street, 02-787 Warsaw, Poland; marzena_tomaszewska@sggw.edu.pl

* Correspondence: kostecka.malgorzatam@gmail.com; Tel.: +48-814-456-846

+ Both authors contributed equally to this work.

\begin{abstract}
The study aimed to evaluate the sustainability of a multi-component education (ABC-HEat) program related to healthy nutrition and lifestyle after three months and nine months and to assess the socioeconomic context in improving teenage nutrition knowledge. The study was designed as a clustered, controlled, education-based intervention. A sample was chosen and allocated into either an educated group (under intervention) or a control group (outside of intervention). The study covered 464 11-12-year-old students (educated/control 319/145). In the educated group, data were collected three times: before education, after three months and after nine months to measure the short- and the long-term effects of education, respectively. In the control group, data were collected in parallel. Changes in nutrition knowledge score (NKS, points) by sex, residence, family affluence scale (FAS) were the main outcome measures. The increase in the NKS was significantly higher in the educated group than in the control group-three months after education on average by 1.4 to 2.7 points (all $p<0.001$ ) in the total sample and all subgroups, and nine months after education in rural residents by 2.2 points $(p<0.001)$ and in the total sample by $0.4(p<0.05)$. In the educated group, the chance of no increase in the NKS was higher in urban than rural residents after three months and nine months (adjusted odds ratios [OR] and 95\% Confidence Intervals [95\% CI]: 3.63, 1.80-7.31 and $2.99,1.60-5.59$, respectively, both $p<0.001$ ) using the increase in the NKS by $\geq 4$ points as a reference. The multi-component education program improved the nutrition knowledge of teenagers in the short term regardless of socioeconomic variables, but in the long term this effect was visible only in rural residents. It suggests that a special path of nutrition education addressed to urban teens may be required.
\end{abstract}

Keywords: adolescent; education; intervention; nutrition knowledge; social factors

\section{Introduction}

Nutrition knowledge forms the basis for shaping attitudes towards foods, nutrition and health and human dietary behaviours [1-3]. Nutrition knowledge, through its direct influence on dietary behaviours, can be considered as an important factor that indirectly 
influences human health. Dietary behaviours are formed in early childhood $[4,5]$ and change throughout the lifespan, but key habits and food preferences are relatively stable over time, e.g., craving for sweets or a tendency to over-consume fats [6-8]. It follows that changing dietary behaviours and developing nutrition knowledge should take place in childhood and adolescence before undesirable dietary habits become established.

The effectiveness of nutrition education depends on many factors, including the content of the program, its goals and duration and the method used that should be adapted to the developmental age of respondents, their perceptive abilities and needs [9-11]. Comparative studies have shown that multi-component intervention is more effective than single-component intervention [12-15], especially if it includes a practical component (e.g., workshops) combined with theoretical messages. In the Canadian program "Action Schools! BC-Healthy Eating", which used a multi-component approach with educational, environmental and family elements, a significant increase in the consumption of fresh vegetables and fruits was found [16]. This finding was confirmed in later studies [15,17-19]. It seems that the success of the program, apart from its complexity, may depend on the complementarity of the program components, as well as the proper identification of health benefits by young people resulting from the adoption of pro-healthy dietary habits $[20,21]$.

The influence of socioeconomic factors on dietary and lifestyle behaviours is well known [22-24]. Many studies show that young people from families with lower socioeconomic status consume less pro-healthy foods such as vegetables and fish [1,25-27], while more foods with lower nutrient contents but higher energy value, e.g., fast foods [28-30]. It has been suggested that the lower socioeconomic status of the family is related to the lower interest of teenagers in a pro-healthy diet [31,32]. Therefore, it can be speculated that family socioeconomic status, determined with parents' education level, family affluence and urban vs. rural residence, is an important factor influencing the nutrition knowledge level in young people [33]. It has been shown that a poorer social environment in which young people grow up can have a devastating effect on nutrition education [34]. Therefore, socioeconomic status may determine the effectiveness of educational programs targeted at adolescents.

The impact of socioeconomic status on the nutrition knowledge level of young people and the effectiveness of nutrition- and health-related education programs has not been known so far. Filling this knowledge gap will identify inequalities in the long-term maintenance of nutrition knowledge and identify groups of children and adolescents that require a special approach when education programs are designed. The aim of the current study was to evaluate the sustainability of a multi-component education program related to healthy nutrition and lifestyle after three months and nine months and to assess the socioeconomic context in improving teenage nutrition knowledge.

\section{Materials and Methods}

\subsection{Study Design and Participants}

The data for this study were collected in Poland in 2015-2016 as a part of the "ABC of Healthy Nutrition" project, the 1st edition of the national multicentre "ABC of Healthy Eating" (ABC-HEat) project (2015-2018) [35]. Data were collected by experienced researchers well trained in collecting dietary data.

The study was designed as a clustered, controlled, education-based intervention. A sample was chosen and allocated (not randomly) into either an educated group (under educational intervention) or a control group (outside of educational intervention).

In the educated group, data were collected three times: (i) before education (at baseline), (ii) after three months ( \pm 2 weeks; 3 month follow-up) to measure the short-term effect of education, (iii) after nine months ( \pm 2 weeks; 9 month follow-up) to measure the long-term effect of education. In the control group, data were collected in parallel.

The study included students of selected elementary schools from urban, suburban and rural areas. The schools (not randomly selected) were located in eight locations covering 
the entire territory of Poland in line with the location of seven academic centres involved in the study (Figure S1).

A school class was the smallest unit in the sample selection. It was decided to start recruitment based on school classes, because students were subject to the same school education and would be at a similar stage of development. Schools were first invited to take part in the study and each student of 4th- and 5th-grade classes of this school (classes that met criteria and teachers who gave their approval) were then invited. More details on the study design and protocol were described previously by Hamulka et al. [35].

School inclusion criteria were:

- a location at a convenient distance from the academic centres (up to $50 \mathrm{~km}$ );

- the consent of the school principal to school participation;

- no previous participation of the school in other nutrition-health education programs.

Participant inclusion criteria were:

- $\quad$ written consent of parents or legal guardians to participate;

- $\quad 4$ th- and 5th-grade classes of elementary school; the expected age of the students was 11-12 years at baseline;

- no disability self-declared by a parent, legal guardian or teacher.

In total, 48 classes from 14 schools were selected across Poland (Figure 1). Initially, 668 students were recruited. A total of 204 participants were excluded from analyses (17 participants because of age and 187 participants due to not attending all stages of the study). The study included 464 teenagers aged $11-12$ years, 216 boys ( $46.6 \%)$ and 248 girls (53.4\%) (Table 1).

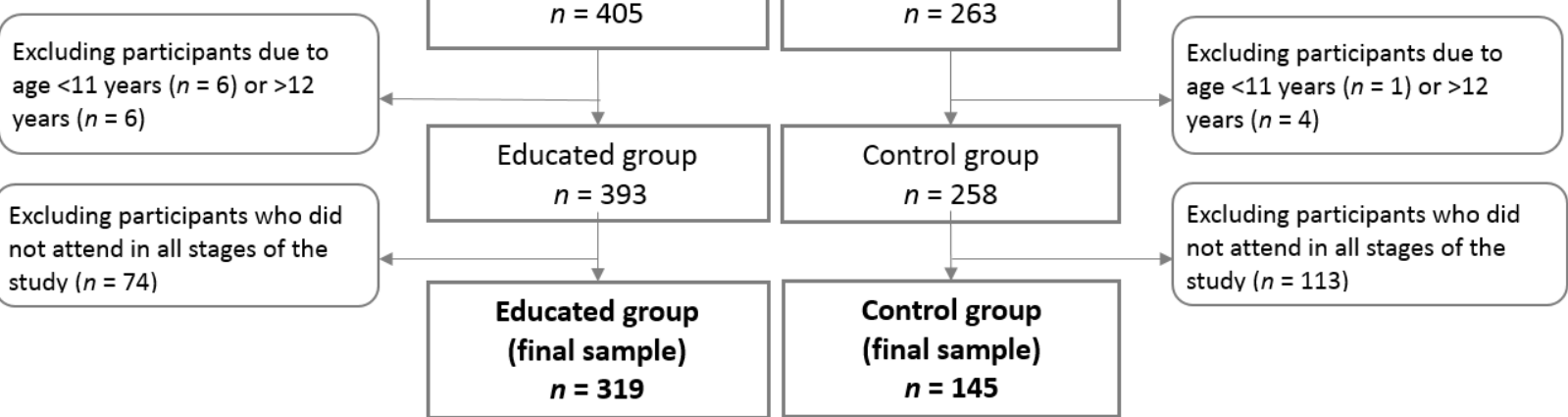

Figure 1. Flow chart of sample collection and study design. 
Table 1. Sample baseline characteristics and changes in nutrition knowledge score (NKS) three months and nine months after education (\% or mean and standard deviation, SD).

\begin{tabular}{|c|c|c|c|c|}
\hline Variables & Total & Educated & Control & $p$-Value \\
\hline Sample size & 464 & 319 & 145 & \\
\hline Sample percentage & 100.0 & 100.0 & 100.0 & \\
\hline Age (years), mean (SD) & $11.9(0.3)$ & $11.9(0.3)$ & $12.0(0.2)$ & 0.20 \\
\hline Gender, $n(\%)$ & & & & 0.16 \\
\hline Girls & $248(53.4)$ & $178(55.8)$ & $70(48.3)$ & \\
\hline Boys & $216(46.6)$ & $141(44.2)$ & 75 (51.7) & \\
\hline Residence, $n(\%)$ & & & & 0.06 \\
\hline Urban & $302(65.1)$ & $217(68.0)$ & $85(58.6)$ & \\
\hline Rural & $162(34.9)$ & $102(32.0)$ & $60(41.4)$ & \\
\hline \multicolumn{5}{|l|}{ Family Affluence Scale, $n(\%)$} \\
\hline Low & $117(25.3)$ & $79(24.9)$ & $38(26.2)$ & 0.86 \\
\hline Higher & $345(74.7)$ & $238(75.1)$ & $107(73.8)$ & \\
\hline \multicolumn{5}{|l|}{ NKS (points), mean (SD) } \\
\hline Baseline & $6.0(2.7)$ & $6.1(2.6)$ & $5.5(2.7)$ & $<0.05$ \\
\hline After 3 months & $7.8(3.0)$ & $8.5(2.8)$ & $6.2(2.9)$ & $<0.001$ \\
\hline After 9 months & $7.9(3.0)$ & $8.3(3.1)$ & $7.2(2.7)$ & $<0.001$ \\
\hline Change after 3 months & $1.8(2.7)$ & $2.4(2.8)$ & $0.6(1.9)$ & $<0.001$ \\
\hline Change after 9 months & $2.0(3.2)$ & $2.1(3.4)$ & $1.7(2.6)$ & $<0.05$ \\
\hline No increase in NKS after 3 months, $n(\%)$ & $166(35.9)$ & $80(25.1)$ & $86(60.1)$ & $<0.001$ \\
\hline Increase in NKS by $1-3$ points after 3 months, $n(\%)$ & $177(38.3)$ & $130(40.7)$ & $47(32.9)$ & \\
\hline Increase in NKS by $\geq 4$ points after 3 months, $n(\%)$ & $119(25.8)$ & $109(34.2)$ & $10(7.0)$ & \\
\hline No increase in KNS after 9 months, $n(\%)$ & $156(33.8)$ & $93(29.2)$ & $63(44.0)$ & $<0.01$ \\
\hline Increase in KNS by $1-3$ points after 9 months, $n(\%)$ & $172(37.2)$ & $128(40.1)$ & $44(30.8)$ & \\
\hline Incerase in KNS by $\geq 4$ points after 9 months, $n(\%)$ & $134(29.0)$ & $98(30.7)$ & $36(25.2)$ & \\
\hline
\end{tabular}

Sample size may vary in variables due to missing data. Family Affluence Scale (low: 0-4 points, higher: 5-7 points). Nutrition knowledge score range: $0-18$ points. $p$-value significance level of Mann-Whitney test (for means) or hi ${ }^{2}$ test, with Yates' correction when necessary (for percentage distribution).

The sample size included in the study (educated/control group 319/145) exceeded the minimum sample size (200/104), which was determined in regard to nutrition knowledge as a key measure of the study. The calculation was based on the expected increase in nutrition knowledge score (see Section 2.4) after a 9 month follow-up and the expected difference between the educated and control groups. With a $5 \%$ significance level and $80 \%$ power, the sample size required approximately 304 respondents (assuming a 2/1 ratio for the educated/control group, i.e., 200/104 respondents and an equal number of respondents in each research centre) at the end of the study, to detect a 50\% difference between the educated group (an increase of 30\%) and the control group (an increase of 15\%) in the increase of nutrition knowledge score, including a 50\% dropout rate (at the end of the study) and a recoding error or missing data rate of $10 \%$.

\subsection{Intervention}

The participants of the educated group were taken over a multi-component education program lasting three weeks and covering five diet-related and lifestyle-related topics, which included various forms of education, from fun to "scientific" cognition. Each topic lasted approximately $180 \mathrm{~min}$ ( $4 \mathrm{~h}$ of school lessons) and was run by a minimum of 3-4 researchers. The program was developed and implemented by academic researchers. Most of the educational activities were carried out in academic centres and the rest in schools. School teachers were not involved in the education program, they were only present during educational activities. Apart from the study, students from both educated and control groups took part in regular school activities containing some content related to nutrition and a healthy lifestyle. The topics and details of the education program are presented in Table S1 and were described previously [35,36]. 


\subsection{Data Collection}

Data related to nutrition knowledge and socioeconomic variables (self-reported) were collected with a short form of a food frequency questionnaire (acronym: SF-FFQ4PolishChildren) dedicated to school-aged children (Figure 2). The questionnaire was developed for the "ABC of Healthy Eating" project and its internal compatibility was tested [37].

\begin{tabular}{|c|c|c|c|c|}
\hline May 2015 & June 2015 & June 2015 & September 2015 & March 2016 \\
\hline $\begin{array}{l}\text { Sample } \\
\text { collection }\end{array}$ & $\begin{array}{l}\text { Baseline } \\
\text { Data collection }\end{array}$ & $\begin{array}{l}\text { Education program } \\
\text { (lasting } 3 \text { weeks) }\end{array}$ & $\begin{array}{l}\text { After } 3 \text { months from baseline } \\
\text { Data collection } \\
\text { (3-month follow-up) }\end{array}$ & $\begin{array}{l}\text { After } 9 \text { months from baseline } \\
\text { Data collection } \\
\text { (9-month follow-up) }\end{array}$ \\
\hline
\end{tabular}

Activities performed in both, educated and control groups.

Activities performed in the educated group only.

Figure 2. Timeline and activities of the ABC-HEat program.

\subsection{Nutrition Knowledge}

The nutrition knowledge level was determined based on eighteen questions and is presented in the Supplementary Materials (Table S2) $[35,36]$. The questions were developed based on a questionnaire described by Whati et al. [38] and adapted to Polish conditions and education [37]. Correct answers were scored with 1 point and wrong or "I don't know" answers or missing data were scored with 0 points. Points were summed up for each respondent to calculate the nutrition knowledge score (NKS, in points; ranged from 0 to 18). While developing the NKS, the authors were inspired by similar scores previously described by other researchers and authors [38-41]. In the present study, the value of Cronbach's alpha for an NKS of 0.685 can be interpreted as sufficient internal consistency of the score (acceptable internal consistency of a score/scale is $\geq 0.7$ while results $\geq 0.6$ have been also reported as satisfactory or sufficient) [42,43]. A correlation coefficient of 0.68 was found for the NKS when the test-retest reproducibility of the questionnaire (SF-FFQ4PolishChildren) was assessed in 11-15-year-old adolescents [37].

\subsection{Socioeconomic Data}

Respondents were distinguished as rural or urban residents, based on the data collected with the questionnaire. The socioeconomic status was determined with the Family Affluence Scale (FAS) based on household characteristics (the details were described previously) $[35,37]$. For international use, the scale was developed with the Health Behaviour in School-aged Children (HBSC) cross-national study. For national use, the scale was adopted by the Polish team of the HBSC study [44]. The scale was composed of four questions related to having a family owning a car/van/truck, traveling away on holiday with the family, having a bedroom, having a family which owns computers/laptops/tablets, with answers to choose from. For each answer, points were assigned (Table S3 in Supplementary Materials). To calculate FAS, the points were summed up for each respondent (range 0 to 7). Based on FAS distribution, the respondents were divided into two categories: low FAS (0-4 points; <25th quartile) and higher FAS (5-7 points). In the present study, the value of Cronbach's alpha for the FAS (with four components) of 0.634 can be interpreted as sufficient internal consistency of the scale $[4,42]$ as mentioned above (see Section 2.4) and it was a higher result than for the Polish adaptation of the scale reported by Mazur (0.497) [44].

\subsection{Data Analysis}

The normality of the distribution of continuous variables was assessed with the Shapiro-Wilk test. For continuous variables, the data were presented as means with $95 \%$ confidence intervals (95\% CIs) or standard deviations (SDs), while categorical variables were presented as a sample percentage (\%). As the NKS (in points) was not normally 
distributed, the differences between the means of two independent groups (educated vs. control) were verified with a Mann-Whitney test, the means of two dependent groups (baseline vs. follow-up) were compared using a Wilcoxon test. The percentage distribution of categorical variables was determined with a chi-squared test with Yates' correction when necessary.

The following three groups of respondents were considered: (i) with no increase in the nutrition knowledge score, (ii) with an increase in the nutrition knowledge score, (iii) with an increase in the nutrition knowledge score $\geq 4$ points, note: this group was also included in (ii). These three respondent groups (and cutoffs in points) were chosen a priori as optimal for comparison based on the (percentage) distribution of the changes in the NKS after three and nine months and with the assumption that the sample size was adequate for the statistical analysis.

To determine an association between nutrition knowledge and socioeconomic factors (gender, residence, FAS), logistic regression modelling was used to assess the chance of no increase in the nutrition knowledge score after a 3 month or 9month follow-up in respect to the baseline. As a reference, two categories were considered, separately: (i) any increase in the nutrition knowledge score, (ii) an increase in the nutrition knowledge score $\geq 4$ points; the modelled category was no increase. The odds ratios (ORs) and 95\% CI were then calculated. A crude model and a model with an adjustment for gender, age (years), residence (urban, rural) and FAS (three categories: 0-4 points, 5-6 points, 7 points) were created, excluding the modelled variable from the confounders set, respectively. The significance of ORs was assessed by Wald's statistics. The Statistica software package (version 12.0 PL, StatSoft Inc., Tulsa, OK, USA, StatSoft, Krakow, Poland) was used for all data analyses. Statistical significance $(p)$ was considered at three levels: $<0.05,<0.01,<0.001$.

\section{Results}

\subsection{Changes in Nutrition Knowledge Score Three Months after Education}

In the educated group, the increase in the NKS in the total sample and all subgroups (girls, boys, rural residence, urban residence, low FAS, higher FAS) was found, on average by 2.0 to 3.2 points (Table 2 and Figure 3). In the control group, the increase in the NKS averaged 0.6 to 0.7 points in all subgroups except for the low FAS subgroup $(p=0.08)$. In the total sample and all subgroups, the increase in the NKS was significantly higher in the educated group than in the control group, on average by 1.4 to 2.7 points (all $p<0.001$ ).

Table 2. Changes in nutritional knowledge score (points) three months and nine months after education by socioeconomic factors (mean and 95\% confidence interval, 95\% CI).

\begin{tabular}{|c|c|c|c|c|c|c|c|}
\hline Variables & Baseline & $\begin{array}{l}\text { After } 3 \\
\text { Months }\end{array}$ & $\begin{array}{l}\text { After } 9 \\
\text { Months }\end{array}$ & $\begin{array}{l}\text { Change after } \\
3 \text { Months }\end{array}$ & $p$-Value & $\begin{array}{l}\text { Change after } \\
9 \text { Months }\end{array}$ & $p$-Value \\
\hline \multicolumn{8}{|l|}{ Total sample } \\
\hline control & $5.5(5.1 ; 6.0)$ & $6.2(5.7 ; 6.6)$ & $7.2(6.8 ; 7.6)$ & $0.6(0.3 ; 0.9)$ & $<0.001$ & $1.7(1.2 ; 2.1)$ & $<0.001$ \\
\hline Difference & 0.6 & 2.3 & 1.1 & 1.8 & & 0.4 & \\
\hline$p$-value & $<0.05$ & $<0.001$ & $<0.001$ & $<0.001$ & & $<0.05$ & \\
\hline \multicolumn{8}{|l|}{ Girls } \\
\hline educated & $6.6(6.2 ; 7.0)$ & $8.9(8.5 ; 9.4)$ & $8.6(8.2 ; 9.1)$ & $2.4(1.9 ; 2.8)$ & $<0.001$ & $2.0(1.6 ; 2.5)$ & $<0.001$ \\
\hline control & $5.7(5.0 ; 6.4)$ & $6.3(5.6 ; 7.0)$ & $7.3(6.7 ; 8.0)$ & $0.6(0.2 ; 1.0)$ & $<0.01$ & $1.7(1.0 ; 2.3)$ & $<0.001$ \\
\hline Difference & 0.9 & 2.6 & 1.3 & 1.8 & & 0.3 & \\
\hline$p$-value & $<0.05$ & $<0.001$ & $<0.01$ & $<0.001$ & & 0.15 & \\
\hline \multicolumn{8}{|l|}{ Boys } \\
\hline educated & $5.6(5.1 ; 6.0)$ & $7.9(7.5 ; 8.4)$ & $7.8(7.3 ; 8.3)$ & $2.3(1.9 ; 2.8)$ & $<0.001$ & $2.2(1.6 ; 2.8)$ & $<0.001$ \\
\hline control & $5.4(4.8 ; 6.0)$ & $6.1(5.4 ; 6.7)$ & $7.1(6.5 ; 7.7)$ & $0.6(0.1 ; 1.1)$ & $<0.05$ & $1.6(1.0 ; 2.3)$ & $<0.001$ \\
\hline Difference & 0.2 & 1.8 & 0.7 & 1.7 & & 0.6 & \\
\hline$p$-value & 0.61 & $<0.001$ & $<0.05$ & $<0.001$ & & 0.10 & \\
\hline
\end{tabular}


Table 2. Cont.

\begin{tabular}{|c|c|c|c|c|c|c|c|}
\hline Variables & Baseline & $\begin{array}{l}\text { After } 3 \\
\text { Months }\end{array}$ & $\begin{array}{l}\text { After } 9 \\
\text { Months }\end{array}$ & $\begin{array}{l}\text { Change after } \\
3 \text { Months }\end{array}$ & $p$-Value & $\begin{array}{l}\text { Change after } \\
9 \text { Months }\end{array}$ & $p$-Value \\
\hline \multicolumn{8}{|l|}{ Urban } \\
\hline educated & $6.3(5.9 ; 6.6)$ & $8.2(7.8 ; 8.6)$ & $7.9(7.4 ; 8.3)$ & $2.0(1.6 ; 2.3)$ & $<0.001$ & $1.6(1.2 ; 2.0)$ & $<0.001$ \\
\hline control & $4.7(4.2 ; 5.2)$ & $5.3(4.7 ; 5.8)$ & $6.8(6.3 ; 7.4)$ & $0.6(0.2 ; 0.9)$ & $<0.01$ & $2.1(1.5 ; 2.7)$ & $<0.001$ \\
\hline Difference & 1.6 & 2.9 & 1.1 & 1.4 & & -0.5 & \\
\hline$p$-value & $<0.001$ & $<0.001$ & $<0.01$ & $<0.001$ & & 0.27 & \\
\hline \multicolumn{8}{|l|}{ Rural } \\
\hline educated & $5.9(5.4 ; 6.4)$ & $9.1(8.6 ; 9.6)$ & $9.1(8.5 ; 9.6)$ & $3.2(2.6 ; 3.7)$ & $<0.001$ & $3.2(2.5 ; 3.9)$ & $<0.001$ \\
\hline control & $6.8(6.0 ; 7.5)$ & $7.4(6.7 ; 8.2)$ & $7.7(7.0 ; 8.5)$ & $0.7(0.2 ; 1.3)$ & $<0.05$ & $1.0(0.3 ; 1.6)$ & $<0.01$ \\
\hline Difference & -0.9 & 1.7 & 1.4 & 2.5 & & 2.2 & \\
\hline$p$-value & 0.06 & $<0.001$ & $<0.01$ & $<0.001$ & & $<0.001$ & \\
\hline \multicolumn{8}{|l|}{ Low FAS } \\
\hline educated & $5.7(5.1 ; 6.2)$ & $8.7(8.1 ; 9.3)$ & $8.4(7.8 ; 9.0)$ & $3.0(2.4 ; 3.6)$ & $<0.001$ & $2.7(2.0 ; 3.5)$ & $<0.001$ \\
\hline control & $4.4(3.6 ; 5.2)$ & $4.8(4.0 ; 5.5)$ & $6.4(5.6 ; 7.2)$ & $0.3(0.0 ; 0.7)$ & 0.08 & $2.0(1.0 ; 3.0)$ & $<0.001$ \\
\hline Difference & 1.3 & 3.9 & 2.0 & 2.7 & & 0.7 & \\
\hline$p$-value & $<0.05$ & $<0.001$ & $<0.001$ & $<0.001$ & & 0.11 & \\
\hline \multicolumn{8}{|l|}{ Higher FAS } \\
\hline educated & $6.3(6.0 ; 6.7)$ & $8.5(8.1 ; 8.8)$ & $8.2(7.8 ; 8.6)$ & $2.1(1.8 ; 2.5)$ & $<0.001$ & $1.9(1.5 ; 2.3)$ & $<0.001$ \\
\hline control & $5.9(5.4 ; 6.5)$ & $6.7(6.1 ; 7.2)$ & $7.5(7.0 ; 8.0)$ & $0.7(0.3 ; 1.1)$ & $<0.001$ & $1.5(1.0 ; 2.0)$ & $<0.001$ \\
\hline Difference & 0.4 & 1.8 & 0.7 & 1.4 & & 0.4 & \\
\hline$p$-value & 0.16 & $<0.001$ & $<0.05$ & $<0.001$ & & 0.10 & \\
\hline
\end{tabular}

Nutrition knowledge score (range: 0-18). FAS indicates Family Affluence Scale (low: 0-4 points, higher: 5-7 points). Difference calculated as the absolute difference between the educated vs. control group. Change calculated as the difference between follow-up vs. baseline within one group (educated or control). $p$-value-significance level for difference (Mann-Whitney test) or change (Wilcoxon test).

(a)

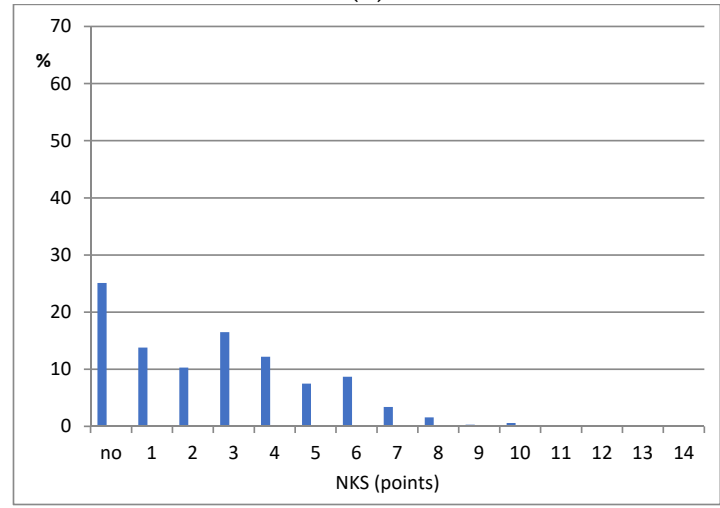

(c)

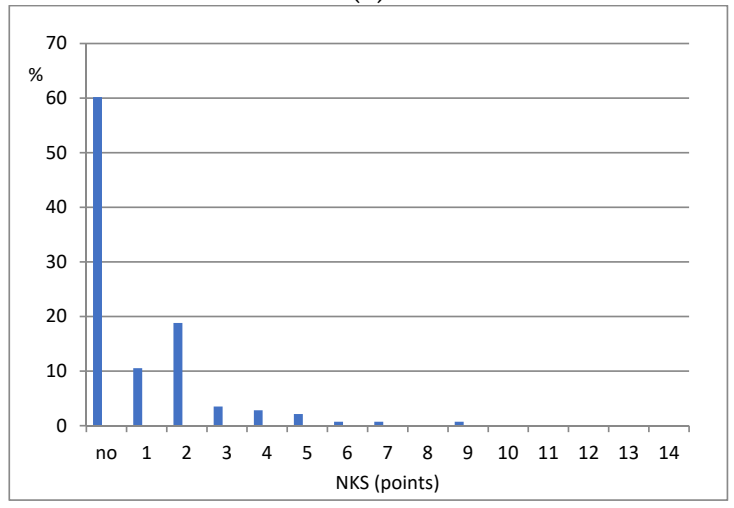

(b)

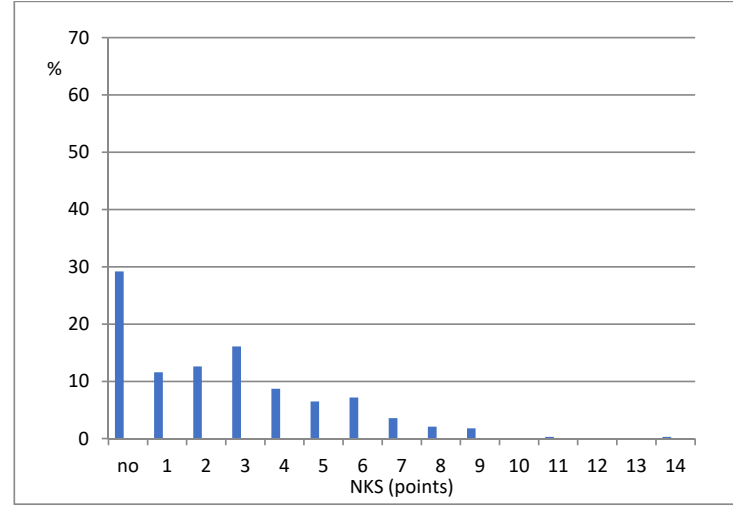

(d)

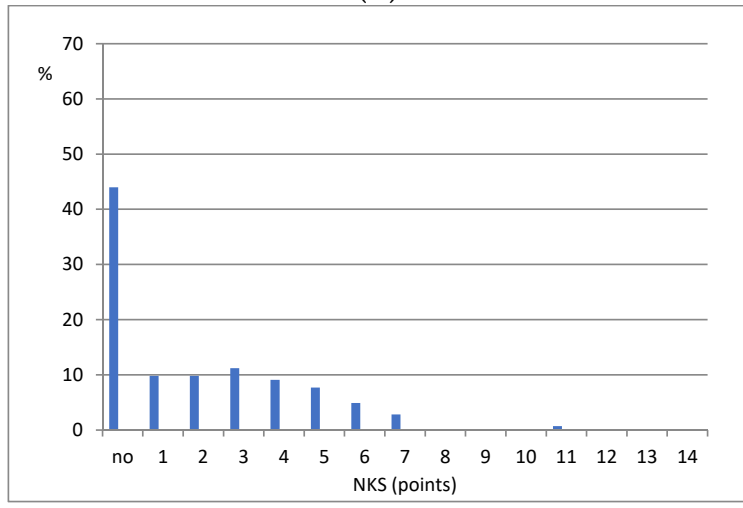

Figure 3. Sample distribution (\%) by changes in nutrition knowledge score (NKS) after three months and nine months. Notes: no-means no increase in NKS; (a) educated group after 3 months; (b) educated group after 9 months; (c) control group after 3 months; (d) control group after 9 months. 


\subsection{Changes in Nutrition Knowledge Score Nine Months after Education}

In the educated group, the increase in the NKS in the total sample and all subgroups (girls, boys, rural residence, urban residence, low FAS, higher FAS) was found to be, on average, by 1.6 to 3.2 points (Table 2 and Figure 3). In the control group, the increase in the NKS averaged 1.0 to 2.1 points in all subgroups. The increase in the NKS was significantly higher in the educated group than in the control group in rural residents (by 2.2 points, $p<0.001$ ) and in the total sample (by $0.4, p<0.05$ ), while there was no significant difference in girls, boys, urban residents and teens with low or higher FAS.

\subsection{The Chance of No Increase in Nutrition Knowledge Score Three Months after Education}

In the educated group, the chance of no increase in the NKS was higher in urban residents than in rural residents, considering both any increase (adjusted OR 2.75, $p<0.01$ ) and an increase by $\geq 4$ points (adjusted OR 3.63, $p<0.001$; Table 4; Table 3) as a reference. A similar association was found in the crude model. In the control group, the chance of no increase in the NKS was higher in the low FAS group (adjusted OR 2.67, $p<0.05$ ) than in the higher FAS group considering any increase as a reference.

Table 3. Odds ratios (95\% Confidence Intervals) for no increase in nutrition knowledge score three months and nine months after education by socioeconomic factors.

\begin{tabular}{cccccc}
\hline \multirow{2}{*}{ Variables } & Models & \multicolumn{2}{c}{ After 3 Months } & \multicolumn{2}{c}{ After 9 Months } \\
\cline { 3 - 6 } & & $\begin{array}{c}\text { No Increase } \\
\text { (Ref.: Any } \\
\text { Increase) }\end{array}$ & $\begin{array}{c}\text { No Increase } \\
\text { (Ref.: Increase by } \\
\geq \text { 4 Points) }\end{array}$ & $\begin{array}{c}\text { No Increase } \\
\text { (Ref.: Any } \\
\text { Increase) }\end{array}$ & $\begin{array}{c}\text { No Increase } \\
\text { (Ref.: Increase by } \\
\geq 4 \text { Points) }\end{array}$ \\
\hline Girls (ref.: boys) & & & & & \\
educated & Crude & $1.10(0.66,1.83)$ & $0.99(0.55,1.78)$ & $0.95(0.58,1.54)$ & $1.12(0.63,1.99)$ \\
& Adjusted & $1.05(0.62,1.77)$ & $0.85(0.46,1.59)$ & $0.92(0.56,1.51)$ & $1.02(0.56,1.87)$ \\
control & Crude & $1.28(0.65,2.52)$ & $2.33(0.56,9.80)$ & $0.85(0.35,2.05)$ & $1.34(0.58,3.12)$ \\
Urban (ref.: rural) & Adjusted & $1.29(0.64,2.58)$ & $2.36(0.52,10.59)$ & $0.85(0.43,1.69)$ & $1.31(0.54,3.19)$ \\
educated & Crude & $2.75 * *(1.45,5.19)$ & $3.57 * *(1.78,7.16)$ & $1.64(0.95,2.83)$ & $3.04 * * *(1.64,5.65)$ \\
& Adjusted & $2.75 * *(1.45,5.20)$ & $3.63 * * *(1.80,7.31)$ & $1.66(0.96,2.89)$ & $2.99 * * *(1.60,5.59)$ \\
control & Crude & $1.06(0.53,2.10)$ & $2.19(0.56,8.46)$ & $0.46 *(0.23,0.92)$ & $0.30 *(0.12,0.76)$ \\
Low FAS (ref.: higher) & Adjusted & $0.77(0.35,1.66)$ & $1.03(0.19,5.57)$ & $0.48(0.23,1.01)$ & $0.38(0.14,1.05)$ \\
educated & Crude & $0.69(0.36,1.33)$ & $0.61(0.30,1.27)$ & $0.62(0.33,1.20)$ & $0.59(0.28,1.23)$ \\
& Adjusted & $0.74(0.38,1.43)$ & $0.67(0.32,1.42)$ & $0.66(0.34,1.27)$ & $0.67(0.31,1.46)$ \\
control & Crude & $2.26(0.96,5.33)$ & $3.90(0.46,33.30)$ & $0.70(0.32,1.51)$ & $0.48(0.19,1.21)$ \\
& Adjusted & $2.67 *(1.08,6.63)$ & $3.73(0.39,35.25)$ & $0.83(0.37,1.86)$ & $0.68(0.25,1.86)$ \\
\hline
\end{tabular}

Sample size may vary in variables due to missing data. FAS indicates Family Affluence Scale (low: 0-4 points, higher: 5-7 points). Adjusted model: odds ratios adjusted for confounders (at follow-up): gender (girls, boys), age (years), residence (urban, rural), FAS (three categories: 0-4 points, 5-6 points, 7 points), excluding the modelled variable from the confounders' set, respectively. Statistically significant (Wald's statistics): ${ }^{*} p$-value $<0.05,{ }^{* *} p<0.01,{ }^{* * *} p<0.001$.

\subsection{The Chance of No Increase in Nutrition Knowledge Score Nine Months after Education}

In the educated group, the chance of no increase in the NKS was higher in urban residents (adjusted OR 2.99, $p<0.001$ ) than in rural residents considering an increase by $\geq 4$ points as a reference. A similar association was found in the crude model. In the control group, the chance of no increase in the NKS was lower in urban residents than in rural residents considering any increase (crude OR $0.46, p<0.05$ ) and an increase by $\geq 4$ points (crude OR $0.30, p<0.01$ ) as a reference; however, the association disappeared after adjustment for confounders. 
Table 4. Sample distribution (\%) by the change in nutrition knowledge score and socioeconomic factors three months and nine months after education.

\begin{tabular}{|c|c|c|c|c|c|c|c|c|c|c|c|c|c|c|c|c|c|c|c|c|c|c|c|c|}
\hline \multirow{3}{*}{ Variables } & \multicolumn{12}{|c|}{ After 3 Months } & \multicolumn{12}{|c|}{ After 9 Months } \\
\hline & \multicolumn{4}{|c|}{ No Increase } & \multicolumn{4}{|c|}{ Any Increase } & \multicolumn{4}{|c|}{ Increase $\geq 4$ Points } & \multicolumn{4}{|c|}{ No Increase } & \multicolumn{4}{|c|}{ Any Increase } & \multicolumn{4}{|c|}{ Increase $\geq 4$ Points } \\
\hline & Total & Edu & Con & $p$-Value & Total & Edu & Con & $p$-Value & Total & Edu & Con & $p$-Value & Total & Edu & Con & $p$-Value & Total & Edu & Con & $p$-Value & Total & Edu & Con & $p$-Value \\
\hline Sample size & 166 & 80 & 86 & & 296 & 239 & 57 & & 119 & 109 & 10 & & 156 & 93 & 63 & & 306 & 226 & 80 & & 134 & 98 & 36 & \\
\hline $\begin{array}{l}\text { Sample } \\
\text { percentage }\end{array}$ & 100.0 & 48.2 & 51.8 & & 100.0 & 80.7 & 19.3 & & 100.0 & 91.6 & 8.4 & & 100.0 & 59.6 & 40.4 & & 100.0 & 73.9 & 26.1 & & 100.0 & 73.1 & 26.9 & \\
\hline Gender & & & & 0.42 & & & & 0.16 & & & & 0.17 & & & & 0.36 & & & & 0.41 & & & & 0.25 \\
\hline Girls & 53.6 & 57.5 & 50.0 & & 53.0 & 55.2 & 43.9 & & 55.5 & 57.8 & 30.0 & & 51.3 & 54.8 & 46.0 & & 54.6 & 56.2 & 50.0 & & 48.5 & 52.0 & 38.9 & \\
\hline Boys & 46.4 & 42.5 & 50.0 & & 47.0 & 44.8 & 56.1 & & 44.5 & 42.2 & 70.0 & & 48.7 & 45.2 & 54.0 & & 45.4 & 43.8 & 50.0 & & 51.5 & 48.0 & 61.1 & \\
\hline Residence & & & & $<0.01$ & & & & 0.56 & & & & 0.49 & & & & $<0.001$ & & & & 0.95 & & & & $<0.05$ \\
\hline Urban & 70.5 & 82.5 & 59.3 & & 62.2 & 63.2 & 57.9 & & 55.5 & 56.9 & 40.0 & & 64.1 & 75.3 & 47.6 & & 65.4 & 65.0 & 66.3 & & 56.7 & 50.0 & 75.0 & \\
\hline $\begin{array}{l}\text { Rural } \\
\text { FAS }\end{array}$ & 29.5 & 17.5 & 40.7 & & 37.8 & 36.8 & 42.1 & & 44.5 & 43.1 & 60.0 & & 35.9 & 24.7 & 52.4 & & 34.6 & 35.0 & 33.8 & & 43.3 & 50.0 & 25.0 & \\
\hline Low & 24.1 & 17.5 & 30.2 & & 22.0 & 23.4 & 16.1 & & 24.4 & 25.7 & 10.0 & & 18.1 & 15.2 & 22.2 & & 24.1 & 22.3 & 29.1 & & 27.1 & 23.5 & 37.1 & \\
\hline Higher & 75.9 & 82.5 & 69.8 & 0.08 & 78.0 & 76.6 & 83.9 & 0.31 & 75.6 & 74.3 & 90.0 & 0.47 & 81.9 & 84.8 & 77.8 & 0.37 & 75.9 & 77.7 & 70.9 & 0.29 & 72.9 & 76.5 & 62.9 & 0.18 \\
\hline
\end{tabular}

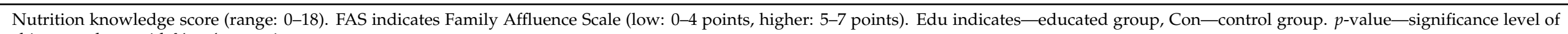
chi-squared test with Yates' correction. 


\section{Discussion}

Considering the total sample, multi-component education improved the nutrition knowledge of teenagers both three and nine months after education. This effect was visible after three months, regardless of sex, place of residence or family affluence, but weakened after nine months, with the exception of rural residents.

The study showed that the implemented multi-component education related to healthy eating, physical activity, culinary experiments and food safety in the long term has improved the nutrition knowledge of teenagers. Considering the total sample, the education program turned out to be effective after both three and nine months. A significant increase in the nutrition knowledge score was noted-in the educated group on average by 2.4 and 2.2 points after three and nine months, respectively. The nutrition knowledge score was also increased in the control group, but the average increase was significantly greater in the educated group than in the control group (by 1.8 and 0.4 points for difference after 3 and 9 months, respectively). The increase in nutrition knowledge in the control group may be attributed to regular school education and out-of-school influences, while in the educated group it was undoubtedly the result of the implemented education program together with school and out-of-school influences. Some previous studies have also evaluated the effectiveness of multi-component intervention models of nutritional and lifestyle education, but the follow-up period from these interventions was shorter and ranged from three to six months [45-47]. Only Zhou et al. [17] studied the effectiveness of pre-/post-intervention within a nine-month follow-up. In contrast to the current study, knowledge scores in the intervention group were significantly lower after the three- and nine-month follow-ups than immediately after the intervention [17].

The studies mentioned above included multi-component intervention packages and were addressed to children and adolescents (Iranian 12-16 years old; Indian 8-18 years old; Chinese 11-14 years old) and their parents and teachers [17,45-47], so they were differently designed in comparison with the current study. In the present study, the education program was related to 11-12-year-old teenagers and was not supported by parents or teachers during education and follow-up. Due to the positive result of the current education program in a nine-month follow-up and the failure of the program by Zhou et al. [17], the current results confirm that the proposed model of education addressed only to 11-12-year-old teens was effective and can be widely recommended.

When considering the residence, the results clearly showed that the increase in nutrition knowledge score was much higher among students living in rural areas than those living in urban areas. For rural teens, these differences remained statistically significant also after nine months from the intervention, being similar to those after three months (average difference was 2.2 and 2.5 points, respectively). Moreover, the chance of the lack of an educational effect, taking into account confounders and regardless of the referent category, was approximately three times greater in urban teens than in rural teens. The positive effect of educational intervention on nutrition knowledge or practice has been shown by several studies of rural residents [18,48-50]. However, the mentioned studies covered only the rural teen populations, thus the effectiveness of nutrition education refers only to them. The current study was more broadly designed and compared the same model of education in different places of residence to assess whether it is a factor influencing the outcome of nutrition knowledge. The findings from the current study are in line with a cross-sectional study carried out in the federal state of Tyrol in western Austria [51], which found associations of higher nutrition knowledge in Austrian students from rural schools and better use of weekly nutrition education classes in comparison to students from urban schools.

It may be speculated that the urban environment provides young people with more stimuli and creates various opportunities to modulate their knowledge, both increasing or decreasing it. Frequent contact with many people, both direct or via social media, and the appearance of much news in the public spaces may weaken previously gained knowledge that has not been consolidated or change it based on false evidence. So-called "fake" news 
related to diet and health is especially frequently distributed via social media and the Internet through idols and influencers [52-54]. Such news may be uncritically and easily adopted by a young audience who do not have the competence to verify it with scientific evidence. There is another possible explanation for the differences between rural and urban teens, although this is only an observation unsupported by scientific investigation. The authors noted a greater interest in the educational program and enthusiasm for the activities that took place in academic centres among rural teens. Moreover, students from rural schools were strongly supported by their teachers to increase student interest, while teachers from urban schools were less (or not) interested in supporting their students. Therefore, it is possible to conclude from the current research, supported by previous results, that rural teens are more sensitive to multi-component nutrition education, while special attention should be paid to urban teens. To achieve a long-lasting educational effect in urban teens, additional activities supporting the previously gained knowledge should be considered. In the authors' opinions, nutrition education programs should be designed to provide additional simple, supportive education a few months after basic education has been completed.

As far as sex subgroups are concerned, the educational effect was similar in girls and boys. The average difference in the increase in nutrition knowledge score, three months after education, was higher in girls/boys who attended the education program than in those out of the program; however, nine months after education, this significance disappeared both in girls and boys. Moreover, the chance of the lack of an educational effect, taking into account confounders and regardless of the referent category, was similar in girls and boys. This finding is in line with a study by Lai Yeung [55]. The author found that 11-16-year-old boys and girls from Hong Kong showed a similar level of nutrition knowledge and, moreover, a similar consumption of vegetables, fruit, milk and bread. In contrast to the current findings and Lai Yeung [55], most studies have found that girls have healthier eating habits and higher nutrition knowledge than boys [56-59]. Crosscultural studies indicate that women focus on healthy eating choices, e.g., avoiding fat-rich foods and salt as well as consuming more fruits and fibre, for better weight control [57,60]. Lipowska et al. [58] suggested that even five-year-old girls are probably aware of the social importance of diet and, thus, internalize healthier eating habits. Altogether, this indicates that while gender plays a significant role in food choices and preferences, the education related to knowledge of nutrition and lifestyle is similarly effective in girls and boys.

Regarding family affluence, the educational effect was similar in teenagers with low and higher family affluence. As was described above with respect to sex, among teenagers with low and higher family affluence, a similar improvement in nutrition knowledge score three months after education was found to have no significant improvement after nine months. Furthermore, the chance of the lack of an educational effect was similar in both teenager groups (with low and higher family affluence). This finding suggests that family affluence is not a factor in shaping long-term maintenance of the nutrition knowledge among Polish teenagers and this factor can be excluded from the confounders set when designing educational programs. It is difficult to compare the current findings with others, because the present study was designed as an intervention with a control group in which the change in nutrition knowledge was a study outcome. Some studies involving adolescents from Europe, Canada and Israel included dietary habits as a study outcome and showed that a high level of inequality in daily food consumption was associated with family wealth [61-63]. However, due to the cross-sectional design of those studies, the changes in nutrition knowledge related to family affluence cannot be interpreted. Further studies of teenagers from other European countries should be carried out to confirm (or not) that family affluence has no impact on the improvement and long-term maintenance of teenagers' nutrition knowledge. 


\section{Strengths and Limitations}

The main advantage of this study was the relatively large sample size (464 teenagers) subjected to a 9 month follow-up. A very rigorous selection of the sample was applied, each participant had to take part in lectures and workshops within all five topics of the education program lasting three weeks; students who missed even one lecture or workshop were excluded. Data collection and all measurements were taken by well-trained researchers with the same type of equipment in all scientific centres to minimize inter-centre differences. Data related to nutrition knowledge and socioeconomic variables were collected with a food frequency questionnaire (SF-FFQ4PolishChildren), which has a known quality and can be recommended to evaluate dietary and lifestyle behaviours among children and adolescents [37].

The main limitation is a lack of random allocation of subjects to the educated and control groups. Unfortunately, the authors were unable to apply the random approach for several reasons. First, for organizational reasons, the authors wanted to choose schools located at a convenient distance from the academic centres (up to $50 \mathrm{~km}$ ). Second, many school principals (surprisingly) did not permit their school to participate in the study. Third, many of the schools had previously participated in other nutrition- or health-related education programs, so they could not be included in our study. There was an element of randomness in the current study since assigning classes to the educated or control group was accidental. Since the study sample is not representative on a national level, study findings do not provide the full picture of the educational effect in 11-12-year-old teens across Poland. The sample could also be biased due to the lack of permission given by the school, teacher or parent to enrol a child in an educational program. However, there is currently no basis to speculate on whether the educational effect would be higher or lower without this bias.

\section{Conclusions}

The results suggest that, in general, the "ABC of Healthy Eating" program is a good model for improving teenagers' nutrition knowledge. Taking into consideration the socioeconomic context, the "ABC of Healthy Eating" program improved the nutrition knowledge of teenagers in the short term regardless of sex, residence or family affluence, but in the long term, this effect was visible only in rural residents. This suggests that although the findings are not representative on the national level, rural teens are more sensitive to multi-component nutrition education, while special attention should be paid to urban teens if nutrition education is being developed and implemented.

Future studies should focus on a comprehensive understanding of barriers attenuating the long-term effectiveness of multi-component, nutrition education in urban teenage residents and, next, developing and testing a special path of nutrition education addressed to urban teens. A simple temporary solution is proposed to design nutrition education programs containing additional simple, supportive education a few months after basic education has been completed. Such a design should strengthen the effects of nutrition education and boost its long-term maintenance in urban teens and bring additional benefits to other socioeconomic groups of teenagers.

Supplementary Materials: The following are available online at https:/ /www.mdpi.com/article/10 $.3390 /$ nu13051661/s1, Figure S1. Location of schools included in the study (up to $50 \mathrm{~km}$ from the academic centres) and academic centres involved in the study (in brackets). Table S1. Topics and details of the education program. Table S2. Questions and correct answers (scored with 1 point) regarding the nutrition knowledge score (NKS). Table S3. Questions and response categories (with scoring) regarding the Family Affluence Scale (FAS).

Author Contributions: J.H., L.W. and J.K. were responsible for the conception and design of the main study and this paper. J.H. was involved in the funding acquisition in respect to the project and managing of the project. J.K. was responsible for the data cleaning and statistical analysis for the main study and this paper. L.W., M.K. and J.K. were responsible for data interpretation for this paper. 
M.K., J.K., M.J.-B., M.T., A.D. and J.H. were responsible for data collection of the main study. L.W. and M.K. were responsible for data visualization. L.W. and M.K. were responsible for writing the original draft of the manuscript. J.H. was responsible for revising the manuscript critically for important intellectual content. All authors have read and agreed to the published version of the manuscript.

Funding: The study was financially supported by the Carrefour Foundation (Agreement ABC No.1/2014; Agreement ABC No. 2/2016) and each scientific centre from sources of the Polish Ministry of Sciences and Higher Education.

Institutional Review Board Statement: The study was conducted according to the guidelines of the Declaration of Helsinki and approved by the Bioethics Committee of the Faculty of Medical Sciences, University of Warmia and Mazury in Olsztyn, Poland in 2010, Resolution No. 20/2010.

Informed Consent Statement: Informed consent was obtained from all teenagers' parents or legal guardians of the teens involved in the study.

Data Availability Statement: Due to ethical restrictions and participant confidentiality, data cannot be made publicly available. However, data from the ABC of Healthy Eating study are available upon request, for researchers who meet the criteria for access to confidential data. Data requests can be sent to the $\mathrm{ABC}$ of Healthy Eating study coordinator (Jadwiga Hamulka).

Acknowledgments: Thanks are expressed to the participants for their contributions to the study and the academic researchers from: Warsaw University of Life Sciences (WULS-SGGW), Gdynia Maritime University, Faculty of Health Sciences, University of Agriculture in Krakow, University of Life Sciences in Lublin, University of Life Sciences in Poznan, University of Warmia and Mazury in Olsztyn, Wroclaw University of Environmental and Life Sciences.

Conflicts of Interest: The authors declare no conflict of interest. The funding sponsors had no role in the study design, data collection, analysis or interpretation of the data, the writing of the manuscript or the decision to publish the results.

\section{References}

1. Czarnocińska, J.; Jeżewska-Zychowicz, M.; Babicz-Zielińska, E.; Kowalkowska, J.; Wądołowska, L. Postawy Względem Żywności, Żywienia i Zdrowia a Zachowania Żywieniowe Dziewczat i Młodych Kobiet w Polsce. Attitudes towards Food, Nutrition and Health and Dietary Behaviours of Girls and Young Women in Poland; Wydawnictwo UWM: Olsztyn, Poland, 2013. (In Polish)

2. Chen, P.J.; Antonelli, M. Conceptual Models of Food Choice: Influential Factors Related to Foods, Individual Differences, and Society. Foods 2020, 9, 1898. [CrossRef]

3. Bauer, J.M.; Reisch, L.A. Behavioural insights and (un) healthy dietary choices: A review of current evidence. J. Consum. Policy 2019, 42, 3-45. [CrossRef]

4. Jeżewska-Zychowicz, M. Zachowania Żywieniowe i Ich Uwarunkowania. Eating Behaviors and Their Determinants; Wydanie II Zmienione; Wydawnictwo SGGW: Warszawa, Poland, 2007. (In Polish)

5. Liu, Y.H.; Stein, M.T. Feeding Behaviour of Infants and Young Children and Its Impact on Child Psychosocial and Emotional Development. Encyclopedia on Early Childhood Development. Updated September 2013. Available online: http://www.childencyclopedia.com/child-nutrition/according-experts/feeding-behaviour-infants-and-young-children-and-its-impact-child (accessed on 25 January 2021).

6. Drewnowski, A.; Mennella, J.A.; Johnson, S.L.; Bellisle, F. Sweetness and food preference. J. Nutr. 2012, 142, 1142S-1148S. [CrossRef]

7. De Cosmi, V.; Scaglioni, S.; Agostoni, C. Early Taste Experiences and Later Food Choices. Nutrients 2017, 9, 107. [CrossRef]

8. Diethelm, K.; Jankovic, N.; Moreno, L.A.; Huybrechts, I.; De Henauw, S.; De Vriendt, T.; González-Gross, M.; Leclercq, C.; Gottrand, F.; Gilbert, C.C.; et al. Food intake of European adolescents in the light of different food-based dietary guidelines: Results of the HELENA (Healthy Lifestyle in Europe by Nutrition in Adolescence) Study. Public Health Nutr. 2012, 15, 386-398. [CrossRef]

9. Carbone, E.T.; Zoellner, J.M. Nutrition and health literacy: A systematic review to inform nutrition research and practice. J. Acad. Nutr. Diet. 2012, 112, 254-265. [CrossRef] [PubMed]

10. Dudley, D.A.; Cotton, W.G.; Peralta, L.R. Teaching approaches and strategies that promote healthy eating in primary school children: A systematic review and meta-analysis. Int. J. Behav. Nutr. Phys. Act. 2015, 12, 28. [CrossRef] [PubMed]

11. Adom, T.; De Villiers, A.; Puoane, T.; Kengne, A.P. School-Based Interventions Targeting Nutrition and Physical Activity, and Body Weight Status of African Children: A Systematic Review. Nutrients 2019, 12, 95. [CrossRef] [PubMed] 
12. McAleese, J.D.; Rankin, L.L. Garden-based nutrition education affects fruit and vegetable consumption in sixth-grade adolescents. J. Am. Diet. Assoc. 2007, 107, 662-665. [CrossRef]

13. Parmer, S.M.; Salisbury-Glennon, J.; Shannon, D.; Struempler, B. School gardens: An experiential learning approach for a nutrition education program to increase fruit and vegetable knowledge, preference and consumption among second-grade students. $J$. Nutr. Educ. Behav. 2009, 41, 212-217. [CrossRef] [PubMed]

14. Prell, H.C.; Berg, M.C.; Jonsson, L.M.; Lissner, L. A school-based intervention to promote dietary change. J. Adolesc. Health 2005, 36, 529. [CrossRef]

15. Ochoa-Avilés, A.; Verstraeten, R.; Huybregts, L.; Andrade, S.; Van Camp, J.; Donoso, S.; Ramírez, P.L.; Lachat, C.; Maes, L.; Kolsteren, P. A school-based intervention improved dietary intake outcomes and reduced waist circumference in adolescents: A cluster randomized controlled trial. Nutr. J. 2017, 16, 79. [CrossRef] [PubMed]

16. Day, M.E.; Strange, K.S.; McKay, H.A.; Naylor, P.J. Action schools! BC-healthy eating. Can. J. Public Health 2008, 99, 328-331. [CrossRef] [PubMed]

17. Zhou, W.J.; Xu, X.L.; Li, G.; Sharma, M.; Qie, Y.L.; Zhao, Y. Effectiveness of a school-based nutrition and food safety education program among primary and junior high school students in Chongqing, China. Glob. Health Promot. 2016, 23, 37-49. [CrossRef] [PubMed]

18. Wang, D.; Stewart, D.; Chang, C.; Shi, Y. Effect of a school-based nutrition education program on adolescents' nutrition-related knowledge, attitudes and behaviour in rural areas of China. Environ. Health Prev. Med. 2015, 20, 271-278. [CrossRef] [PubMed]

19. Raikar, K.; Thakur, A.; Mangal, A.; Vaghela, J.F.; Banerjee, S.; Gupta, V. A study to assess the effectiveness of a nutrition education session using flipchart among school-going adolescent girls. J. Educ. Health Promot. 2020, 9, 183. [CrossRef] [PubMed]

20. Jung, T.; Huang, J.; Eagan, L.; Oldenburg, D. Influence of school-based nutrition education program on healthy eating literacy and healthy food choice among primary school children. Int. J. Health Promot. Educ. 2019, 57, 67-81. [CrossRef]

21. In-Iw, S.; Saetae, T.; Manaboriboon, B. The Effectiveness of School-Based Nutritional Education Program among Obese Adolescents: A Randomized Controlled Study. Int. J. Pediatr. 2012, 2012, 608920. [CrossRef]

22. Skårdal, M.; Western, I.M.; Ask, A.M.; Overby, N.C. Socioeconomic differences in selected dietary habits among Norwegian 13-14 year-olds: A cross-sectional study. Food Nutr. Res. 2014, 58, 23590. [CrossRef]

23. van Lenthe, F.J.; de Bourdeaudhuij, I.; Klepp, K.I.; Lien, N.; Moore, L.; Faggiano, F.; Kunst, A.E.; Mackenbach, J.P. Preventing socioeconomic inequalities in health behaviour in adolescents in Europe: Background, design and methods of project TEENAGE. BMC Public Health 2009, 9, 125. [CrossRef] [PubMed]

24. Maenhout, L.; Peuters, C.; Cardon, G.; Compernolle, S.; Crombez, G.; DeSmet, A. The association of healthy lifestyle behaviors with mental health indicators among adolescents of different family affluence in Belgium. BMC Public Health 2020, $20,958$. [CrossRef]

25. Svastisalee, C.M.; Holstein, B.E.; Due, P. Fruit and vegetable intake in adolescents: Association with socioeconomic status and exposure to supermarkets and fast food outlets. J. Nutr. Metab. 2012, 2012, 185484. [CrossRef] [PubMed]

26. Addressing the Socioeconomic Determinants of Healthy Eating Habits and Physical Activity Levels among Adolescents; WHO Report; World Health Organization: Geneva, Switzerland, 2006.

27. Mazur, J. Health and Health Behaviour of School Children in Poland against the Background of Selected Sociodemographic Conditions; HBSC 2014 Results; Instytut Matki i Dziecka: Warszawa, Polska, 2015. (In Polish)

28. Shahar, D.; Shai, I.; Vardi, H.; Shahar, A.; Fraser, D. Diet and eating habits in high and low socioeconomic groups. Nutrition 2005, 21, 559-566. [CrossRef]

29. Peltzer, K.; Pengpid, S. Correlates of healthy fruit and vegetable diet in students in low, middle and high income countries. Int. J. Public Health 2014, 60, 79-90. [CrossRef] [PubMed]

30. Williamson, V.G.; Dilip, A.; Dillard, J.R.; Morgan-Daniel, J.; Lee, A.M.; Cardel, M.I. The Influence of Socioeconomic Status on Snacking and Weight among Adolescents: A Scoping Review. Nutrients 2020, 12, 167. [CrossRef] [PubMed]

31. Mladenova, S.; Andreenko, E. Influence of socio-economic and demographic factors, feeding and physical activity on nutritional status of 8-15-year-old Bulgarian children and adolescents: Preliminary results. Nutr. Hosp. 2015, 32, 2559-2569. [CrossRef] [PubMed]

32. Darmon, N.; Drewnowski, A. Does social class predict diet quality? Am. J. Clin. Nutr. 2008, 87, 1107-1117. [CrossRef]

33. Said, L.; Gubbels, J.S.; Kremers, S.P.J. Dietary Knowledge, Dietary Adherence, and BMI of Lebanese Adolescents and Their Parents. Nutrients 2020, 12, 2398. [CrossRef]

34. Scaglioni, S.; de Cosmi, V.; Ciappolino, V.; Parazzini, F.; Brambilla, P.; Agostoni, C. Factors Influencing Children's Eating Behaviours. Nutrients 2018, 10, 706. [CrossRef]

35. Hamulka, J.; Wadolowska, L.; Hoffmann, M.; Kowalkowska, J.; Gutkowska, K. The effect of an education program on nutrition knowledge, attitudes toward nutrition, diet quality, lifestyle, and body composition in Polish teenagers. The ABC of Healthy Eating project: Design, protocol, and methodology. Nutrients 2018, 10, 1439. [CrossRef]

36. Wadolowska, L.; Hamulka, J.; Kowalkowska, J.; Ulewicz, N.; Hoffmann, M.; Gornicka, M.; Bronkowska, M.; Leszczynska, T.; Glibowski, P.; Korzeniowska-Ginter, R. Changes in sedentary and active lifestyle, diet quality and body composition nine months after an education program in Polish students aged 11-12 years: Report from the ABC of healthy eating study. Nutrients 2019, 11, 331. [CrossRef] 
37. Kowalkowska, J.; Hamulka, J.; Wojtas, N.; Czlapka-Matyasik, M.; Kozirok, W.; Bronkowska, M.; Sadowska, J.; Naliwajko, S.; Dziaduch, I.; Koronowicz, A.; et al. Reproducibility of a Short-Form, Multicomponent Dietary Questionnaire to Assess Food Frequency Consumption, Nutrition Knowledge, and Lifestyle (SF-FFQ4PolishChildren) in Polish Children and Adolescents. Nutrients 2019, 11, 2929. [CrossRef]

38. Whati, L.H.; Senekal, M.; Steyn, N.P.; Nel, J.H.; Lombard, C.; Norris, S. Development of a reliable and valid nutritional knowledge questionnaire for urban South African adolescents. Nutrition 2005, 21, 76-85. [CrossRef]

39. Kowalkowska, J.; Wadolowska, L.; Czarnocinska, J.; Czlapka-Matyasik, M.; Galinski, G.; Jezewska-Zychowicz, M.; Bronkowska, M.; Dlugosz, A.; Loboda, D.; Wyka, J. Reproducibility of a Questionnaire for Dietary Habits, Lifestyle and Nutrition Knowledge Assessment (KomPAN) in Polish Adolescents and Adults. Nutrients 2018, 10, 1845. [CrossRef] [PubMed]

40. Grosso, G.; Mistretta, A.; Turconi, G.; Cena, H.; Roggi, C.; Galvano, F. Nutrition knowledge and other determinants of food intake and lifestyle habits in children and young adolescents living in a rural area of Sicily, South Italy. Public Health Nutr. 2013, 16, 1827-1836. [CrossRef] [PubMed]

41. Vereecken, C.; De Pauw, A.; Van Cauwenbergh, S.; Maes, L. Development and test-retest reliability of a nutrition knowledge questionnaire for primary-school children. Public Health Nutr. 2012, 15, 1630-1638. [CrossRef] [PubMed]

42. Cronbach, L.J. Coefficient alpha and the internal structure of tests. Psychometrika 1951, 16, 297-334. [CrossRef]

43. Taber, K.S. The Use of Cronbach's Alpha When Developing and Reporting Research Instruments in Science Education. Res. Sci. Educ. 2018, 48, 1273-1296. [CrossRef]

44. Mazur, J. Family Affluence Scale-Validation study and suggested modification. Hygeia Public Health 2013, 48, $211-217$.

45. Shah, P.; Misra, A.; Gupta, N.; Hazra, D.K.; Gupta, R.; Seth, P.; Agarwal, A.; Gupta, A.K.; Jain, A.; Kulshreshta, A.; et al. Improvement in nutrition-related knowledge and behavior of urban Asian Indian school children: Findings from the 'Medical education for children/adolescents for realistic prevention of obesity and diabetes and for healthy aGeing' (MARG) intervention study. Br. J. Nutr. 2010, 104, 427-436. [CrossRef]

46. Ghasab Shirazi, M.; Kazemi, A.; Kelishadi, R.; Mostafavi, F. The improvement of dietary behaviors among Iranian adolescent girls: A theory-based randomized controlled trial. Health Educ. Res. 2019, 34, 159-172. [CrossRef] [PubMed]

47. Singhal, N.; Misra, A.; Shah, P.; Gulati, S. Effects of controlled school-based multi-component model of nutrition and lifestyle interventions on behavior modification, anthropometry and metabolic risk profile of urban Asian Indian adolescents in North India. Eur. J. Clin. Nutr. 2010, 64, 364-373. [CrossRef] [PubMed]

48. Roy, S.K.; Fuchs, G.J.; Mahmud, Z.; Ara, G.; Islam, S.; Shafique, S.; Akter, S.S.; Chakraborty, B. Intensive nutrition education with or without supplementary feeding improves the nutritional status of moderately-malnourished children in Bangladesh. J. Health Popul. Nutr. 2005, 23, 320-330. [PubMed]

49. Inayati, D.A.; Scherbaum, V.; Purwestri, R.C.; Wirawan, N.N.; Suryantan, J.; Hartono, S.; Bloem, M.A.; Pangaribuan, R.V.; Biesalski, H.K.; Hoffmann, V.; et al. Improved nutrition knowledge and practice through intensive nutrition education: A study among caregivers of mildly wasted children on Nias Island, Indonesia. Food Nutr. Bull. 2012, 33, 117-127. [CrossRef]

50. Reinbott, A.; Schelling, A.; Kuchenbecker, J.; Jeremias, T.; Russell, I.; Kevanna, O.; Krawinkel, M.B.; Jordan, I. Nutrition education linked to agricultural interventions improved child dietary diversity in rural Cambodia. Br. J. Nutr. 2016, 116, 1457-1468. [CrossRef] [PubMed]

51. Egg, S.; Wakolbinger, M.; Reisser, A.; Schätzer, M.; Wild, B.; Rust, P. Relationship between nutrition knowledge, education and other determinants of food intake and lifestyle habits among adolescents from urban and rural secondary schools in Tyrol, Western Austria. Public Health Nutr. 2020, 17, 1-12. [CrossRef]

52. Sinapuelas, I.C.; Ho, F.N. Information exchange in social networks for health care. J. Consum. Mark. 2019, 36, 692-702. [CrossRef]

53. Vestergaard, M.G. The Danish Veterinary and Food Administration's Fight against Fake Nutrition News on Digital Media. Tidsskr. Medier Erkendelse Formidl. 2019, 7, 21.

54. Pilgrim, K.; Bohnet-Joschko, S. Selling health and happiness how influencers communicate on Instagram about dieting and exercise: Mixed methods research. BMC Public Health 2019, 19, 1054. [CrossRef]

55. Lai Yeung, W.L. Gender Perspectives on Adolescent Eating Behaviors: A Study on the Eating Attitudes and Behaviors of Junior Secondary Students in Hong Kong. J. Nutr. Educ. Behav. 2010, 42, 250-258. [CrossRef]

56. Peykari, N.; Tehrani, F.R.; Eftekhari, M.B.; Malekafzali, H.; Dejman, M.; Neot, R.; Djalalinia, S. Peer-based study on adolescence nutritional health: A lesson learned from Iran. J. Pak. Med. Assoc. 2011, 61, 549-554. [PubMed]

57. Wardle, J.; Haase, A.M.; Steptoe, A.; Nillapun, M.; Jonwutiwes, K.; Bellisle, F. Gender differences in food choice: The contribution of health beliefs and dieting. Ann. Behav. Med. 2004, 27, 107-116. [CrossRef] [PubMed]

58. Lipowska, M.; Lipowski, M.; Jurek, P.; Jankowska, A.M.; Pawlicka, P. Gender and Body-Fat Status as Predictors of Parental Feeding Styles and Children's Nutritional Knowledge, Eating Habits and Behaviours. Int. J. Environ. Res. Public Health 2018, 15, 852. [CrossRef]

59. Caine-Bish, N.L.; Scheule, B. Gender differences in food preferences of school-aged children and adolescents. J. Sch. Health 2009, 79, 532-540. [CrossRef] [PubMed] 
60. Gharib, N.; Rasheed, P. Energy and macronutrient intake and dietary pattern among school children in Bahrain: A cross-sectional study. Nutr. J. 2011, 10, 62. [CrossRef] [PubMed]

61. Zaborskis, A.; Grincaite, M.; Kavaliauskiene, A.; Tesler, R. Family structure and affluence in adolescent eating behaviour: A cross-sectional study in forty-one countries. Public Health Nutr. 2020, 1-12. [CrossRef] [PubMed]

62. Fismen, A.S.; Samdal, O.; Torsheim, T. Family affluence and cultural capital as indicators of social inequalities in adolescent's eating behaviours: A population-based survey. BMC Public Health 2012, 12, 1036. [CrossRef]

63. Handeland, K.; Kjellevold, M.; Wik Markhus, M.; Eide Graff, I.; Frøyland, L.; Lie, Ø.; Skotheim, S.; Stormark, K.M.; Dahl, L.; Øyen, J. A Diet Score Assessing Norwegian Adolescents' Adherence to Dietary Recommendations-Development and Test-Retest Reproducibility of the Score. Nutrients 2016, 8, 467. [CrossRef] 